\title{
Condução e contracondução na dança de salão
}

Carolina Polezi ${ }^{1}$

\author{
Anderson Luiz Barbosa Martins ${ }^{2}$
}

\section{Resumo}

Tendo em vista que a dança de salão é atravessada por forças políticas, econômicas e sociais, esse artigo visa analisar as transformações dessa prática debatendo o conceito de condução como ferramenta de controle do corpo da mulher pelo homem como uma relação de poder construída na Europa desde o início do século XV e que ainda se apresenta como forma de governo predominante nessa dança social. A partir dessa problematização os autores pensam a contraconduta como modo de experimentação que escapa a heteronormatividade e cria novas possibilidades para a expressão e vida e outro modo de dançar a dois.

Palavras-chave: Dança-de-salão; Contraconduta; Gênero; Política.

\section{Leading and conter - conduct at social dance}

\section{Abstract}

Given that social dance is crossed by political, economical and social forces, this article aims to analyze the transformations on this practice and to discuss the concept of leading as a control tool of the women's body by the men as a relation of power built in Europe at the begining of the fifteenth century and which has been presented as the prevailing form of government at the social dance. Based on that problematization, the authors think counterconduct as an experimentation that escapes from heteronormativity and creates new possibilities for expression and life. So then another way of dancing in pairs.

Keywords: Social dance; Counter-conduct; Gender; Politics.

\section{Introdução}

Tendo em vista seu caráter histórico, a dança de salão está fortemente implicada com os processos que operam na constituição do corpo. "Pois o corpo é, ele próprio um processo. Resultado provisório das convergências entre técnica e sociedade, sentimentos e objetos, ele pertence menos à natureza do que à história" (SANT’ ANNA, 1995, p.12).

Dentre as técnicas fundamentais dessa dança, a condução nos chama mais atenção, pois é a ação de o homem levar a mulher a realizar seguidos movimentos, de forma a construir essa prática (NOGUEIRA, 2009). Para Pacheco (1998, p.11) "condução significa os procedimentos pelos quais homem conduz/dirige a mulher durante a evolução dos passos dancísticos". Nessa

\footnotetext{
1 Doutoranda em Educação pela Faculdade de Educação da Universidade de Campinas, Campinas, carolinapolezi@gmail.com.

${ }^{2}$ Professor no SENAC Campinas, Campinas, anderluma@hotmail.com.
}

Periódico Horizontes - USF - Itatiba, SP - Brasil - e019032 
perspectiva, há um discurso defendendo que cabe ao homem conduzir e decidir quais passos serão executados, pois suas características masculinas como "segurança, determinação, objetividade, habilidade e domínio técnico" (GAIO; FIORANTI; COAN, 2009, p. 48) são tidas como mais apropriadas ao melhor desempenho da condução, enquanto à mulher cabe ser conduzida por causa de suas características, ditas naturais, tais como "sensibilidade, empatia, criatividade e emotividade" (GAIO; FIORANTI; COAN, 2009, p. 48). A condução nos parece um dos princípios básicos da dança de salão na perpetuação do discurso e práticas das relações de poder.

Em 1982, Foucault relatava em um de seus últimos textos, O Sujeito e o Poder, que o "exercício do poder não deveria ser buscado do lado da violência e da luta, nem do lado do contrato ou da aliança voluntária. [...Pois o poder] é menos da ordem do afrontamento entre dois adversários, ou do vínculo de um com relação ao outro, do que da ordem do 'governo'" (1995, p. 244). A noção de governo é tomada em sua significação bastante ampla, não se referindo apenas às formas de governo político, mas recobrindo modos de ação mais ou menos refletidos e calculados, destinados a agir sobre as possibilidades de ação dos outros indivíduos. Governar, neste sentido, consiste em "conduzir condutas" e "ordenar a probabilidade". O termo "conduta" deve ser entendido, ao mesmo tempo, como o ato de conduzir os outros e dispor a maneira de se comportar num campo aberto de possibilidades. Nas palavras do autor, pensando o poder pelo novo prisma, torna-se possível afirmar:

Ele é um conjunto de ações sobre ações possíveis; ele opera sobre o campo de possibilidade onde se inscreve o comportamento dos sujeitos ativos; ele incita, induz, desvia, facilita ou torna mais difícil, amplia ou limita, torna mais ou menos provável; no limite, ele coage ou impede absolutamente, mas é sempre uma maneira de agir sobre um ou vários sujeitos ativos, e o quanto eles agem ou são suscetíveis de agir. Uma ação sobre ações (FOUCAULT, 1995, p. 243).

Foucault insistiu bastante sobre a relação entre a doutrina da liberdade política e a delegação aos indivíduos de seu próprio governo: quanto mais liberdade, mais disciplina e autorregulação de si. Numa entrevista de 1980, o autor afirma que "não se podia liberar os indivíduos sem adestrá-los" (FOUCAULT apud MICHAUD, 2000, p. 24, tradução nossa) ${ }^{3}$. Ao

\footnotetext{
${ }^{3}$ On ne pouvait libérer les individus sans les dresser.
} 
analisar as técnicas de conduta em dança, Green (apud VALLE, 2012) salienta que os praticantes da dança talvez não entendam que suas escolhas não são tão livres como poderiam pensar. Diante das técnicas integradoras e produtivas da disciplina que invadem a profundidade das consciências e dos corpos através de um aprendizado intensificado, multiplicado, muitas vezes repetitivo, alunos e professores talvez não se deem conta do grande processo de normatização ao qual estamos submetidos e que produz, no interior de cada indivíduo, uma cisão e um esforço de se conformar aos valores sociais, tensão culpabilizadora que provoca a homogeneização dos comportamentos.

O que estou tentando ressaltar aqui, é que os bailarinos podem perceber uma tal felicidade ou prazer em treinar seus corpos através de rigorosas 'técnicas' e eles podem usar a autovigilância para se certificar de que eles estão executando movimentos corretamente. No entanto, eles não podem ver que este 'prazer' é socialmente produzido e amarrado em uma determinada ética corporal que está ligada a uma economia social e política maior (GRENN apud VALLE, 2012, p.71).

Ao traçar um paralelo entre o estudo do movimento e do corpo com as pesquisas das relações de poder de Michel Foucault, Silva (2012) afirma que o espaço e o tempo fazem parte dos operadores de controle, sendo assim, nas escolas de dança há toda uma organização e reorganização dos espaços e a aceleração do tempo impostos pelas práticas disciplinares que são articuladas pelos movimentos dos alunos. Dessa forma, os dispositivos de saber-poder são exercidos através de sistemas de comunicação, redes de informação, atividades de enquadramento que controlam o espaço e o tempo, mas também, os gestos, as maneiras de sentir, amar, criar, perceber, imaginar, de se vestir, embelezar-se, fruir etc., num processo que é interiorizado e reativado pelos próprios sujeitos, o qual pode ser chamado de um estado de alienação autônoma.

\section{Contexto sociopolítico da dança de salão}

Os primeiros movimentos para a dança de salão nascem na Europa durante o Renascimento, nos séculos XV e XVI, principalmente nas cortes. Nas camadas menos privilegiadas da sociedade eram desenvolvidas as danças populares. Em meio às grandes 
transformações da época, as danças sociais passaram a ser não só uma prática de lazer para estes grupos da sociedade, mas um exercício do poder para a nobreza.

No Brasil só se tornou amplamente praticada com a vinda da família real portuguesa a partir de 1808 e as danças aqui praticadas tiveram principalmente influência cultural da Espanha com o fandango e as danças sapateadas, de Madrid, e Paris com as gavotas e minuetos, e mais tarde com a valsa vienense (FERREIRA, 2009), a primeira dança em par enlaçada na qual os dançarinos se dedicavam somente ao seu par.

O início do século XX é marcado por muitas novidades e transformações dos hábitos dos cariocas devido a medidas adotadas por D. João VI. A urbanização do Rio de Janeiro cresce com a chegada do bonde elétrico, ampliando o comércio, o deslocamento e os passeios. A vida cultural ganha mais dinamismo, pois as pessoas passam a frequentar mais os teatros e a vida noturna se anima. Assim, segundo Oliveira (2009), as danças sociais também foram introduzidas no país e acabaram se misturando com outros ritmos, principalmente os de origem africana, multiplicando-se os saraus, festas e bailes.

Era um momento de grandes modificações nos costumes e hábitos do carioca. O curioso, é que a mulher tão restrita à vida privada, dona-de-casa e mãe zelosa, podendo frequentar poucos espaços públicos, como a igreja (assim como a casa era considerado um lugar sagrado), passa a ser 'dama' ao se introduzir na sociedade, através da dança de salão (OLIVEIRA, 2009, p.10).

É nesse cenário de transformação que a mulher de família passa a transitar mais em teatros, parques, confeitarias, clubes (em geral grêmios), onde se promoviam os bailes de dança de salão (OLIVEIRA, 2009), apesar de sempre estar acompanhada pelo marido, amiga ou familiar. A dança e a música eram as principais formas de lazer dos cidadãos do Rio de Janeiro, mas a dança era tida, sobretudo, como sinônimo de boa educação e recomendado como atividade física (FERREIRA, 2009).

Dada a importância da dança e da música pelos habitantes da cidade como principal forma de lazer, os colégios do Rio de Janeiro começaram a ensiná-la em sua grade disciplinar com a ambição pedagógica de corrigir para formar um bom cidadão saudável e trabalhador. Assim, além do aprendizado da técnica da dança e da performance corporal, essas instituições disciplinares ensinavam técnicas de conduta que estavam ligadas a uma maneira de se portar, 
modos de se relacionar com os outros e consigo mesmo, que antes mesmo de serem reforçados no colégio, eram ensinados dentro de casa, pelas mães principalmente.

Essa vocação pedagógica, que não se restringia somente às escolas e famílias, também se operava nas fábricas, hospitais, casernas, sanatórios e prisões. Desse modo, a mulher era educada para ser dama, pois além de passar toda a tradição, as regras e etiquetas sociais, ela também era responsável pela educação dos filhos de modo a perpetuar a "boa educação e os bons costumes". Aos homens era ensinada a postura correta, a simplicidade dos movimentos para não parecerem efeminados, a liderança e condução de uma dama com firmeza. Às mulheres era ensinada a forma correta de se portar, falando baixo, sendo discretas e sentando de pernas fechadas, além de costumes para que se tornassem boas mães e esposas. "A dança de salão servia também como 'treino' para a vida, demarcando claramente as funções e deveres de homens e mulheres socialmente" (OLIVEIRA, 2009, p. 18).

As normas sociais que orientavam os indivíduos valorizavam modelos de conduta rigidamente estabelecidos. A busca de felicidade, por exemplo, estava associada ao desempenho adequado do papel institucional ao qual o indivíduo era chamado a aderir: ser bom pai, boa mãe, boa esposa, bom trabalhador, bom estudante, bom cidadão, e assim por diante. A docilidade dos corpos era a consequência desse arranjo sociocultural, sendo também a garantia de seu bom funcionamento. Tratava-se, portanto, de uma configuração social no território do governo liberal que oferecia estabilidade e segurança, em proveito da liberdade. Com efeito, o enquadramento disciplinar diminuía tanto as possibilidades de escolha pessoal quanto o peso das responsabilidades individuais.

A primeira metade do século XX é marcada por importantes conquistas femininas como o direito ao voto, que nos EUA veio em 1920, no Brasil em 1932 e na França somente em 1945. A Segunda Guerra Mundial (1939-1945) gerou uma grande escassez de mão de obra masculina na Europa causada pelas mortes dos contingentes de operários que foram lutar na guerra, esse evento permitiu às mulheres europeias ocupar postos de trabalho antes somente realizados por homens.

Numa entrevista intitulada A sociedade disciplinar em crise, Michel Foucault (2003) anuncia tal crise nos países industrializados, nos quais tanto a sociedade como os indivíduos passam por uma mudança que os torna cada vez mais independentes e menos submetidos aos mecanismos de normalização, tal como descrito por suas pesquisas. Para Foucault, a norma seria 
sempre algo produzido pela ordem social para disciplinar os corpos e realizar, então, a gestão dos viventes no espaço social. Portanto, seria produzida e instituía por uma modalidade de poder, denominado disciplinar.

No tempo que se segue ao fim da Segunda Guerra Mundial, as revoltas contra a ordem disciplinar multiplicaram-se, ganhando expressão coletiva e política. As lutas promovidas por movimentos dos negros, das mulheres, dos estudantes e de outras minorias, tinham em comum o combate ao conservadorismo da ordem burguesa, centrada na moral patriarcal e na rigidez das organizações hierárquicas e burocráticas. Esses movimentos de resistência e contraconduta que tencionaram as estruturas da sociedade disciplinar buscavam a espontaneidade, os direitos civis das minorias, a experimentação de novas formas de sociabilidade, a igualdade de direitos entre mulheres e homens, a liberdade sexual e de expressão, assim como de certas condições de subjetivação e formas de sofrimento.

No interior desse contexto também está inserida a dança de salão. As séries de transformações que ocorreram socialmente, principalmente na vida das mulheres, modificaram não só os espaços de dança de salão e seus frequentadores como as possibilidades de relação entre damas e cavalheiros, entre espaços e atores-sociais. De acordo com Oliveira (2009), algumas mudanças ainda não são bem aceitas pelos praticantes, como o baile de ficha, pois este vem proporcionando uma maior autonomia para as mulheres, uma vez que elas podem tomar a iniciativa de escolher o seu parceiro de dança. Contudo, o discurso conservador e machista, que permeia os salões de baile, afirma que as tradicionais relações de gênero que definiam os papéis masculino e feminino estão se descaracterizando, ou seja, perdendo os valores antigos, pois estão ficando muito liberais, fazendo com que a dança perca a sua "essência".

Os grandes e irreversíveis avanços para a autonomia da mulher seguem na segunda metade do século XX com a criação da minissaia pelo estilista francês André Courrèges, com o amor livre e a liberdade sexual pregados pelo movimento hippie e com o advento da pílula contraceptiva, que em 10 anos alcançou o número de 10 milhões de usuárias no mundo e derrubou drasticamente a natalidade. Todos esses elementos trouxeram novo protagonismo e autonomia da mulher sobre seu próprio corpo e suas decisões, marcando a emancipação feminina e uma transformação social incontestável.

O surgimento da AIDS na década de 1980 leva o debate sobre a sexualidade e o sexo Periódico Horizontes - USF - Itatiba, SP - Brasil - e019032 
seguro à grande mídia, discutindo um tema que ainda era tabu para grande parcela da população. No âmbito político, ascendia ao poder a primeira ministra britânica, Margaret Thatcher, também conhecida como a "Dama de Ferro" em 1983, e o Paquistão, um país islâmico, tem pela primeira vez uma primeira-ministra, Benazir Butho, eleita em 1988.

Nos anos 1990/2000 as mulheres entram definitivamente para o mercado de trabalho, no qual apesar de terem posições inferiores aos homens e ganharem menos para exercerem as mesmas funções, expondo o machismo vivo e entranhando na sociedade, ascendem e galgam a cada dia novas posições, e se consolidam como destacadas executivas. A mulher passa a ter liberdade para escolher seus próprios caminhos, ainda que o machismo seja vigente e a cobrança por uma posição de "mulher tradicional" seja constante. Para Goldenberg, "as transformações do papel da mulher no mundo público afetaram, dramaticamente, todos os seus papéis sociais. Tudo mudou nas relações afetivo-sexuais e uma série de novos desejos e exigências surgiram em função da independência econômica da mulher" (2000, p. 114).

Apesar de todos os avanços conquistados no último século, o machismo resiste em nossa sociedade e é latente no cotidiano feminino e principalmente nos salões de baile, onde as diferenças anatômicas entre homens e mulheres continuam sustentando, de forma naturalizada, "a diferença socialmente construída entre os gêneros" (BOURDIEU, 2007, p.20). De acordo com Bourdieu (1998), a diferença anatômica entre os órgãos sexuais é usada como justificativa para a diferença socialmente construída entre os gêneros e, principalmente, da divisão social do trabalho. Com efeito, essa construção social do corpo biológico tende a determinar em nossa sociedade os papéis masculinos e femininos, seus vestuários, seus modos de se relacionar e de se portar, que envolvem, entre diversos aspectos, as desigualdades sociais de gênero.

É através desses "tristes gêneros" (ROLNIK, 1998), com sua lógica binária de oposição e contradições, que a dança de salão propaga uma mensagem de dominação masculina através da ideia de que o homem deve tomar as decisões de conduzir a mulher. No plano do visível, há uma guerra entre identidades sexuais que podem ser vistas de inúmeras maneiras, quando se afirma, por exemplo, ser traços dos homens a proteção, dominação, força e vigor, enquanto a mulher se encaixa no papel de submissa, pequena e sensível para que se mantenha o equilíbrio do casal (SILVEIRA, 2012). No plano do invisível a prática de dançar é modulada segundo um processo de produção da diferença, uma vez que cabe ao homem o exercício da criação, expressão e musicalidade ao ser o 
condutor e propor os passos, enquanto a mulher tem suas possibilidades limitadas ao se deixar ser conduzida, com reduzidas chances de realizar as mesmas atividades masculinas.

[... A] dança pode ser entendida como uma dentre as várias instâncias culturais que "fabricam" homens e mulheres de determinados tipos, é preciso, a partir daí, analisarmos as formas pelas quais as identidades de gênero são construídas, para pensarmos nas diferentes possibilidades ou modos de subjetivação e singularização vivenciados por homens e mulheres nesse contexto (ANDREOLI, 2010, p. 116).

A desigualdade de gênero perpassa pela dominação da mulher pelo homem e isso se dá coletiva e individualmente, atribuindo ao homem privilégios materiais, culturais e simbólicos (WELZER-LANG, 2001). Dentro da perspectiva da dança de salão a dominação coletiva e nos salões de baile acontecem no discurso de poder do homem em ser o propositor e criador da dança e também individual ao manifestar tais relações através da condução do movimento, limitando a dama em seu universo artístico. Nessa atividade "[...] os papéis dos homens e das mulheres são definidos claramente: para eles, cabe a posição de comando, virilidade e força; enquanto que, para elas, ficam os movimentos de leveza, charme e sensualidade" (POLEZI, SILVEIRA, 2017, p. 68).

Como exemplo podemos citar alguns estudiosos, professores e importantes referências para a dança de salão. Ried (2003) afirma: "é o cavalheiro a quem cabe conduzir e à dama, ser conduzida (...) cabe a ele decidir formalmente quais passos e figuras serão executados", (p.37). também Abreu et al (2008) “O homem que tem a iniciativa da condução, de dar o primeiro passo. A mulher precisa deixar ser conduzida..." (p. 652). Gaio, Fioranti e Coan (2009) verificaram em suas pesquisas que os professores de dança não identificam a posição feminina dentro da dança de salão como desigual comparada ao masculino. Ao contrário, acreditam que a função mais importante da mulher é "embelezar" e "florear" a dança com charme e feminilidade, como podemos verificar na passagem a seguir: "O conduzir do cavalheiro exige segurança, determinação, objetividade, habilidade e domínio técnico, enquanto que o seguir da dama, por sua vez, requer sensibilidade, empatia, criatividade e emotividade" (RIED, 2003, p. 37) ${ }^{4}$.

\footnotetext{
${ }^{4}$ A exemplo podemos citar autores argentinos que nos fornece Silveira (2012): Nau-Klapwijk (2006), Labraña e Sebastian (2000) e Romay (2006). Todos esses autores constroem o perfil do masculino como o forte, vigoroso,

Periódico Horizontes - USF - Itatiba, SP - Brasil - e019032
} 
Esses corpos são disciplinados por saberes e práticas que os atingem, transformando-se em que Foucault (1993) chamou de corpos dóceis, pois são obedientes do ponto de vista político e da subversão, mas fortes do ponto de vista da utilidade econômica. Sendo assim, os alunos de dança de salão, não conseguem imaginar a quantas normas os movimentos e os corpos estão sujeitos. Isso quer dizer que todos os movimentos produzidos pela dança são codificados pela nossa cultura, produzidos através do treinamento e disciplinarização. Por essa razão, os atos de romper, de contraconduzir, de transversalizar as normas estabelecidas apresentam grande resistência.

A noção do político em dança está, portanto, atrelada à ideia de resistência. Mas o que é resistir? Como se apresentaria a resistência na dança contemporânea? A resistência está sempre presente nos trabalhos que tratam do tema da arte e política justamente por ser esta a principal ação de uma obra de arte: resistir ao tempo, aos conceitos e, em especial, ao poder. Para Foucault (1976), onde há poder, há resistência (GUZZO, SPINK, 2015, p. 10).

Em A Vontade de Saber (1999), Foucault acreditava que as formas de resistências de poder sobre a vida deviam se apoiar precisamente naquilo que ele investiu, isto é, na vida mesma: "a vida como objeto político foi de algum modo tomada ao pé da letra e voltada contra o sistema que tentava controlá-la" (Foucault, 1999, p.136). Seguindo uma inspiração foucaultiana, entendemos a necessidade contemporânea de problematizar nas formas de condução na dança de salão o conjunto das forças e funções que resistem aos diagramas de poder. Trata-se, portanto, da transformação em nossos corpos, em que, experimentamos o limite do que somos, somos forçados a inventar uma saída na produção de outros modos de condução na dança de salão.

\section{Contraconduta na dança de salão}

É nesse contexto cultural, social e político que trazemos para o debate o conceito de contraconduta (FOUCAULT, 1995) na prática da dança de salão. A contraconduta pode ser

dominador e protetor, enquanto à mulher cabe a submissão, sensibilidade e feminilidade. "la mujer se deberá entregar como una sonámbula, para poder sentir y acompanãr mejor a su hombre" (NAU-KLAPWIJK, 2006, p.169, apud SILVEIRA, 2014, p.7).

Periódico Horizontes - USF - Itatiba, SP - Brasil - e019032 
entendida como uma abertura de novas possibilidades, que, apesar do estranhamento, pode se opor às condutas estabelecidas. Sendo assim ela pode ser considerada um ato de resistência e liberdade, não somente para os parâmetros sociais, mas também sobre nós mesmos. Nesse sentido, a dança como modo político ${ }^{5}$ busca uma nova perspectiva de mundo mais justo e mais ético, uma vez que os discursos atravessam os sujeitos e podem ocupá-los de formas diferentes (FOUCAULT, 1993). De acordo com o autor o conceito de contraconduta pode ser entendido como:

[...] movimentos que têm como objetivo outra conduta, isto é: querem ser conduzidos de outro modo, por outros condutores e por outros pastores, para outros objetivos e para outras formas de salvação, por meio de outros procedimentos e outros métodos. São movimentos que também procuram, eventualmente em todo o caso, escapar da conduta dos outros, que procuram definir para cada um a maneira de se conduzir (FOUCAULT, 2008, p. 256-257).

O conceito de contraconduta originalmente não foi pensado para a dança, mas foi bem trabalhado por Valle e Icle (2014), aplicado aos princípios do movimento e do corpo. Para os autores, a contraconduta aplicada à dança pode ser compreendida como "um processo de resistência a uma cultura e saberes hegemônicos dessa arte e de campos diversos - que estão sempre em relação. A criação seria, assim, um exercício de liberdade em relação à resistência" (VALLE, ICLE 2014, p. 145).

Sob o viés desse estudo, o conceito de contraconduta pode ser explorado de três formas. A primeira buscar "escapar" das condutas conhecidas dos movimentos padrão de cada ritmo, ampliando a criatividade e trazendo outras vivências e experiências para essas danças. A segunda é de contraconduzir os discursos incutidos na dança de salão estereotipando essa prática e não permitindo a evolução crítica da mesma, que se mantém estruturalmente inalterada há mais de um século. Por fim, o conceito de contraconduta é a oposição a uma estrutura desigual de gênero e

\footnotetext{
${ }^{5}$ A reflexão sobre as estruturas que sustentam as posições dentro da condução na dança de salão possui em seu cerne o debate político. Nesse contexto a palavra política tem significado que vai além do domínio das práticas de Estado, se refere à reflexão sobre as relações entre os sujeitos com suas estruturas de poder organizadas a partir de regras e normas - que não são necessariamente jurídicas e legais (PASSOS, BARROS, 2015). Essa leitura do conceito de política nos dá dimensão não somente das macrorrelações, mas, sobretudo, dos arranjos locais indicando esta dimensão micropolítica das relações de poder (FOUCAULT, 1993). Por isso podemos afirmar que a reflexão, o debate e a intervenção na estrutura da condução na dança de salão vai além de uma problemática dancística e técnica, ela é, antes de tudo, uma problemática política.
}

Periódico Horizontes - USF - Itatiba, SP - Brasil - e019032 
sexista perpetuada pelas estruturas da dança de salão ao colocar a mulher sob um papel secundário na criação e proposição dos movimentos, da musicalidade, da espacialização e da expressão.

Por outro lado, a contraconduta também tem um sentido pessoal de reflexão interior de não aceitar o hábito, a repetição, a cópia e a ordem estabelecida. Ao modificar a conduta e com o corpo desenhar uma nova forma de dançar, expressamos através de movimentos nossa visão de mundo naquele instante efêmero do movimento. Isso quer dizer que a contraconduta na dança de salão pode ser utilizada como uma prática de se conduzir diferente do conhecido e como exercício de análise dos atravessamentos discursivos aos quais os corpos estão subordinados na dança, possibilitando a multiplicação de discursos e abertura para novas possibilidades de criação.

Algumas experiências de contracondutas vêm se expandindo e ganhando força ao longo de todo o Brasil. Um movimento recente, mas consistente e articulado une essas propostas, que apesar de suas singularidades entendem que a diferença é a grande potência do movimento. 0 Laboratório de Condução Compartilhada, coordenado por Carolina Polezi junto ao grupo de dança de salão na Unicamp (2015 e 2016) se consolidou em um método que traz a mulher para conduzir os movimentos na dança de salão e amplia as possibilidades de criação e escuta na dança a dois e atualmente é amplamente trabalhado pela pesquisadora e outros profissionais. Paola Vasconcelos, no Rio Grande do Sul, traz o movimento argentino do tango queer para pensar uma dança de salão queer, expandindo a proposta para as várias modalidades de dança a dois brasileira e logra incorporar a dança de salão um grupo que antes ficava apartado dessa prática. Em Belo Horizonte a professa transexual e lésbica Laura James dirige sua escola de dança Ata-me, "que adota uma pedagogia queer no ensino das danças a dois [no qual] praticantes são estimuladas/os a aprender ambos os papeis e a formar pares de dança independentes de gênero" (PAZETTO; SAMWAYS, 2018, p. 175). Ela também promove mensalmente o Forró Queer, espaço de prática do forró livre dos estereótipos de gênero. O grupo "Mulheres que conduzem" promove aulas de dança de salão apenas com integrantes mulheres e também realiza práticas de forró e o TEM - Tango entre Mulheres - desconstruindo a ideia tradicional de um casal formado por um homem e uma mulher para a dança a dois. Débora Pazetto e Samuel Samways vêm desenvolvendo um modo de dançar a dois com influência do Contato Improvisação, em que eles borram os territórios dos movimentos, da música e a corporeidade típica de cada ritmo da 
dança de salão e se permitem transitar por tudo isso através da Condução Mútua, "[...] nesse modelo ambos são conduzidos e conduzem simultaneamente" (PAZETTO; SAMWAYS, 2018, p.175). A Cia de Dança Casa 4 Produções vem correndo o Brasil e América do Sul apresentando o espetáculo "Salão" que conta um pouco da experiência de quatro homens homossexuais que sofrem preconceitos dentro da dança de salão. Sem esquecer a Dois Rumos Cia de Dança que promove mensalmente o já tradicional "Baile Contemporâneo de Dança de Salão" um espaço livre para dançar como desejar e expressar o movimento e a dança das mais diversas formas, sempre de maneira acolhedora para receber todos que queiram se aventurar em propostas que contraconduzem os modelos tradicionais de dançar a dois.

\section{Considerações Finais}

No encontro com a obra de Foucault, pensar depende de um encontro, de uma violência, de forças desconhecidas que esvaziam nossas certezas. Nesse sentido, pensar não é a tentativa de descobrir a verdade, mas a criação do novo. E, se pensar é criar, é porque faz nascer o que ainda não existe, ao invés de simplesmente representar o que já está dado. Portanto, o pensamento é produtor de diferença, não de similitude. Pensar, enquanto experimentação, faz advir o novo, uma vez que cria novas possibilidades para a vida, novas possibilidades de vida. Pensar é, antes de tudo, resistir, não deixar que os valores se fixem onde estão, tornar as coisas móveis, desterritorializá-las, operar o movimento próprio do nômade. Nessa via, encontramos, nas teorias de Michel Foucault e seus intercessores, uma "caixa de ferramentas" que nos permite desnaturalizar a condução como totalidade, abrindo espaço para a emergência de outros modos de pensar a condução na dança de salão e seus efeitos na produção da subjetividade.

\section{Referências}

ABREU, E., et al. Timidez e motivação em indivíduos praticantes de dança de salão. Revista da Faculdade de Educação Física da UNICAMP, Campinas, v.6, p.649-664, jul. 2008.

ANDREOLI, G. S. Dança, gênero e sexualidade: um olhar cultural. Revista Conjectura, Caxias do Sul, v.15, n.1, p.107-118, jan.-abr. 2010. 
BOURDIEU, P. Conferência do prêmio Goffman: a dominação masculina revisitada. In: LINS, D. A dominação masculina revisitada. Campinas: Papirus, 1998, p.11-27.

BOURDIEU, P. A dominação masculina. Trad. Maria Helena Kühner. 5. ed. Rio de Janeiro: Bertrand Brasil, 2007.

FERREIRA, J. M. Dança de salão: novas configurações do campo. 2009. Monografia (Bacharelado em Dança) - Departamento de Arte Corporal/Centro de Ciências da Saúde, Universidade Federal do Rio de Janeiro, Rio de Janeiro, 2009.

FOUCAULT, M. Vigiar e punir: nascimento da prisão. 10. ed. Petrópolis: Vozes, 1993.

FOUCAULT, M. O sujeito e o poder. In: RABINOW, P.; HUBERT, D. Michel Foucault - uma trajetória filosófica. Rio de Janeiro: Forense Universitária, 1995, p.231-249.

FOUCAULT, M. História da sexualidade 1: a vontade de saber. Rio de Janeiro: Graal, 1999.

FOUCAULT, M. A sociedade disciplinar em crise. In: Motta, M. B. Ditos \& Escritos IV. Michel Foucault: estratégia, poder-saber. Rio de Janeiro: Forense Universitária, 2003, p.267-269.

FOUCAULT, M. Segurança, território e população. Martins Fontes: São Paulo, 2008.

GAIO, R.; FIORANTE, F.; COAN, A. B. Corpo e movimento na dança de salão: discussão sobre gênero. Coleção Pesquisa em Educação Física, v.8, n.2, p. 45-52, 2009.

GOLDENBERG, M. Os novos desejos: das academias de musculação às agências de encontros. In: GOLDENBERG, M. Rio de Janeiro: Record, 2000, p.41-54.

GUZZO, M. S. L.; SPINK, M. J. P. Arte, dança e política(s). Psicologia \& Sociedade, v.27, n.1, p.312, 2015.

MICHAUD, I. Des modes de subjectivation aux techniques de soi: Foucault et les identités de notre temps. In: MICHAUD, I. (Org.). Michel Foucault: de la guerra des races au biopouvoir. Paris: PUF, 2000, p.11-39.

NOGUEIRA, K. Quem conduz na dança? uma nova realidade para o século XXI. Disponível em: http://dancasalaojoinville.com/blog/2009/10/conducao-homemx-mulher. Acesso em: 02 jul. 2016.

OLIVEIRA, H. A. G. Relações de gênero: uma investigação sobre o atual papel das damas nos bailes de dança de salão. 2009. Monografia (Bacharelado em Dança) - Departamento de Arte Corporal Escola de Educação Física e Desportos Centro de Ciências da Saúde Universidade Federal do Rio de Janeiro, Rio de Janeiro, 2009. 
PACHECO, A. J. P. Educação física e dança: uma análise bibliográfica. Pensar a Prática, Rio de Janeiro, p.156-171, jun.-jun. 1998.

PASSOS, E.; BARROS, R. B. A cartografia como método de pesquisa-intervenção. In: PASSOS, E.; KASTRUP, V.; ESCÓSSIA, L. Pistas do método da cartografia: pesquisa-intervenção e produção de subjetividade. Porto Alegre: Sulina, 2015, p.17-31.

PAZETTO, D.; SAMWAYS, S. Para além de damas e cavalheiros: uma abordagem queer das normas de gênero na dança de salão. Revista Educação, Artes e Inclusão, Florianópolis, v.14, n.3, p.157-179, 2018.

POLEZI, C.; SILVEIRA, P. V. Contracondutas no ensino e prática da dança de salão: a dança de salão queer e a condução compartilhada. Revista Presencia, Montevideo, n.2, p.67-83, 2017.

RIED, B. Fundamentos de dança de salão. Londrina: Midiograf, 2003.

ROLNIK, S. Tristes Gêneros. In: LINS, D. A dominação masculina revisitada. Campinas: Papirus, 1998, p.63-68.

SANT' ANNA, D. Políticas do corpo. Estação liberdade: São Paulo, 1995.

SILVA, E. C. O movimento como dispositivo de poder. Revista de Pós-Graduação em Dança. v.1, n.1, p.40-53, 2012.

SILVEIRA, P. V. Diálogos de um ser a dois: uma perspectiva para dançar tango. 2012. Trabalho de Conclusão de Curso (Bacharel em Dança) - Universidade Federal do Rio Grande do Sul, Porto Alegre, 2012.

VALLE, F. P. Contraconduta da criação: um estudo com alunos da graduação em dança. 2012. 157f. Tese (Doutorado em Educação) - Educação da Faculdade de Educação da Universidade Federal do Rio Grande do Sul, Porto Alegre, 2012.

VALLE, F. P.; ICLE, G. Contraconduta como criação jogos de enunciações na e sobre a dança. Repertório, Salvador, n.23, p.145-156, 2014.

WELZER-LANG, D. A construção do masculino: dominação das mulheres e homofobia. Estudos Feministas, n.481, p.460-482, 2001.

Recebido em fevereiro de 2019.

Aprovado em abril de 2019. 